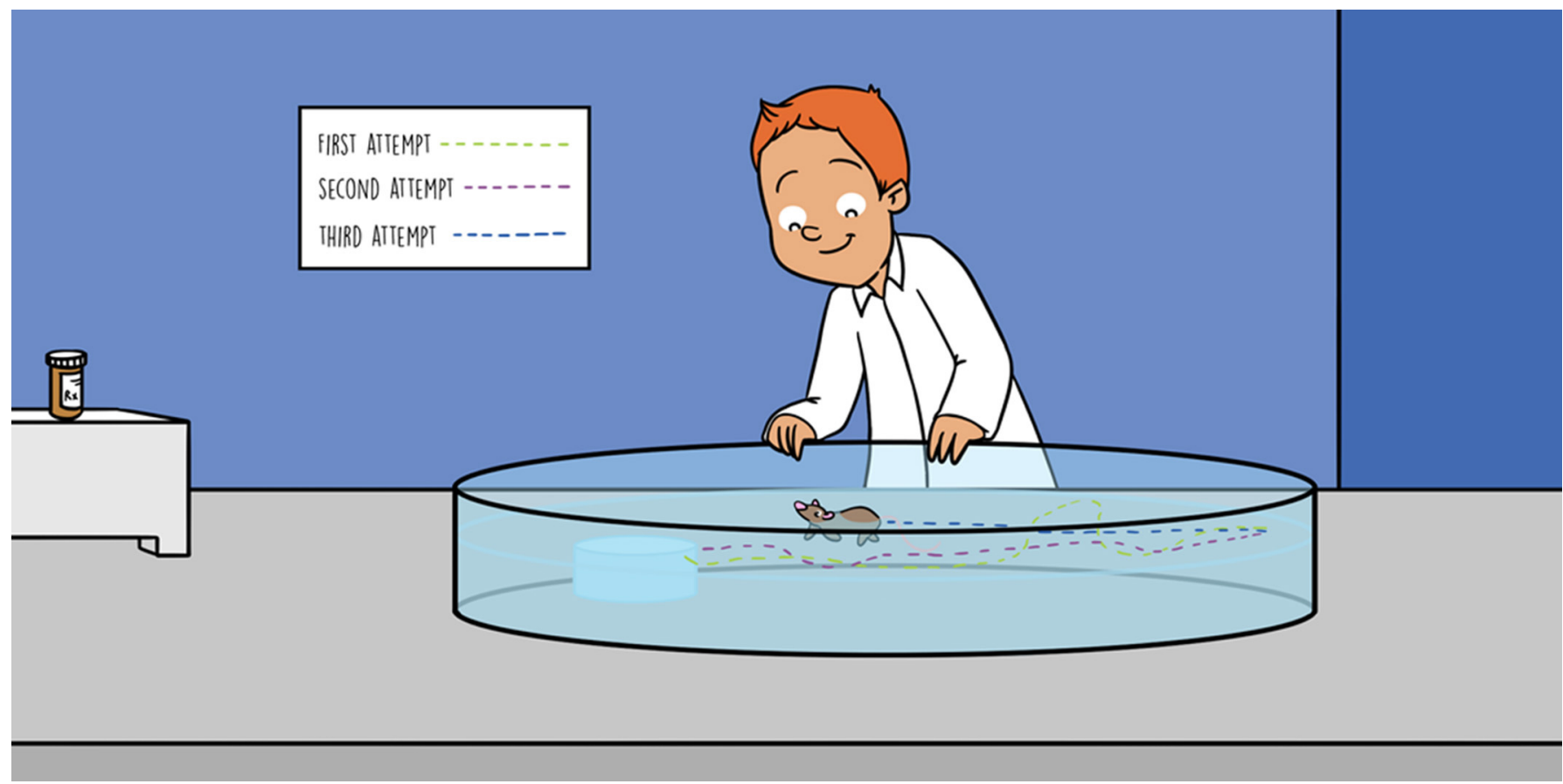

\title{
HOW DO YOU TEST A RAT"S MEMORY?
}

\section{David W. Wright *}

Emergency Medicine, School of Medicine, Emory University, Atlanta, GA, United States

YOUNG REVIEWERS:

DRUMMON-

DVILLE

ELEMENTARY

SCHOOL

AGES: $10-11$

\section{MEMORY}

The ability of the brain to recall past experiences or information.
Brain injury often impairs a person's ability to remember. To find new drugs that improve memory after a brain injury, scientist must rely on experiments in animals such as rats. But how do you test the memory in rats? One way is to use a pool of colored water, called the Morris water maze. In this maze, rats have to "remember" where to go to get out of the water. The more a rat's memory has improved, the quicker it finds its way out of the water (rats do not like being in water). This test can also be used to compare two different drug treatments. It is an important tool for new drug discovery.

\section{FINDING NEW TREATMENTS FOR BRAIN INJURY USING ANIMALS}

One of the major purposes of the brain is memory. When a person suffers from a brain injury, memory is often damaged. In order to find new treatments to help bring memory back, scientist need to test many drugs. These tests are most often performed with animals because research on actual people is much more expensive and hard to do. Using animals allows the scientist to recreate the same type of 


\section{Figure 1}

How do you test a rats memory? (Art by Jessica Forsstrom).

\section{EXPERIMENT}

An action or process set up to find out whether something works or is true.

\section{MORRIS WATER}

\section{MAZE}

One of the most widely used tasks in behavioral science for studying the processes and mechanisms of learning and memory.

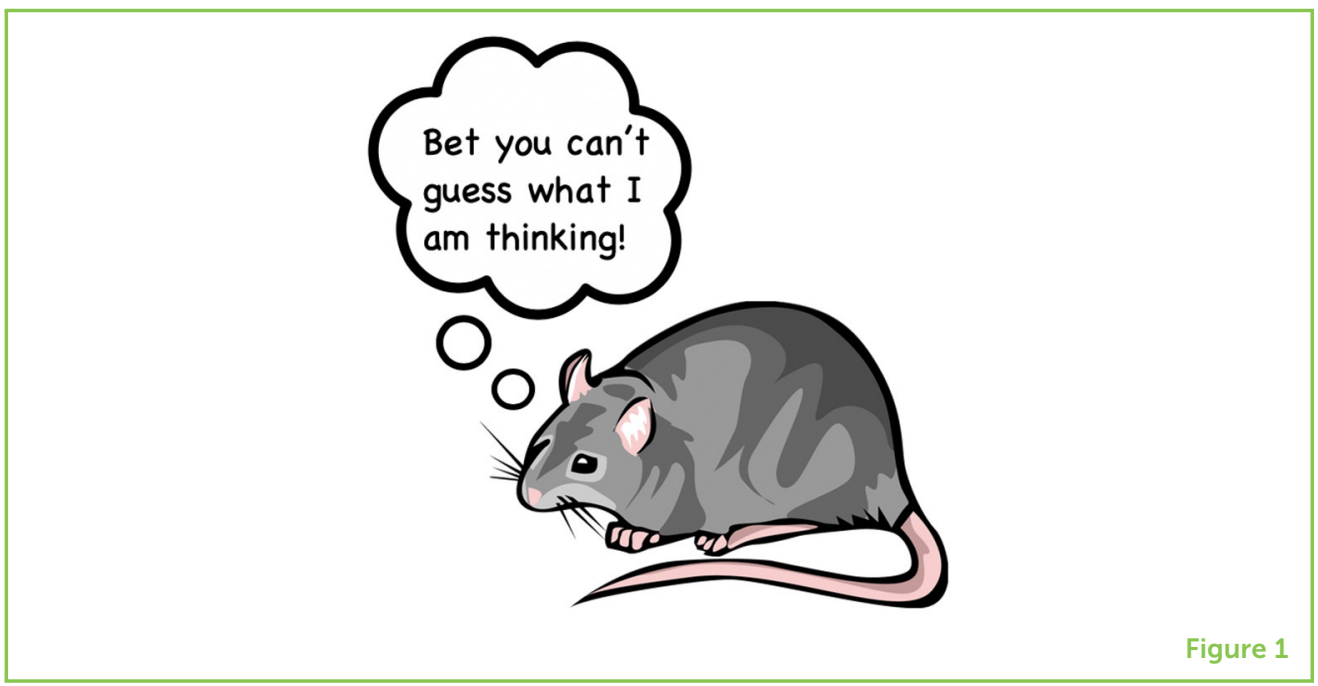

injury in every animal, run the tests several times to be sure the answer is correct, and try new drugs when the safety of the drug is not known. Rats and mice are the most common animals used because they are plentiful and easy to handle. To see if a new drug works to improve memory after a brain injury, the scientist would cause a brain injury in several rats and give the new drug to half of the rats. The other half would not get the drug (known as the control group). Then, they would set up a test to see if the memory in rats that got the new drug was better than the rats that did not.

\section{HOW DO YOU TEST MEMORY IN A RAT?}

This is a really good question! We have no idea what a rat thinks, much less what a rat remembers Figure 1. You cannot ask a rat questions; you cannot have it take a written test. A rat will not respond if you ask it to shake its head yes or no. In fact, it really will not respond to anything you ask at all.

So, how do we use rats in experiments to test the brain's function, such as whether a rat can learn new information or has developed a memory? How can we tell which rats have impaired memory, or are not thinking correctly? And how can we tell if a new drug works to help an injured rat's brain to recover more quickly?

There are several ways to test whether a rat can learn new memories. One method is called the Morris water maze Figure 2. It is a type of puzzle for the rat-a test to see if the rat can get better at remembering its surroundings in order to avoid something unpleasant.

Unpleasant? Well, rats can swim, but they do not like water. So, when placed into a round tank of water, a rat will eagerly swim to find a way out. In the case of the Morris water maze, the sides of the tank are too 


\section{Figure 2}

A navigational memory test used mainly with rats and mice. A non-transparent liquid is placed in a tank with a submerged platform. Rats are put into the tank and swim until they find the platform. Each time they are put in, they learn how to get to the platform quicker using a shorter path. (Art by Jessica Forsstrom).

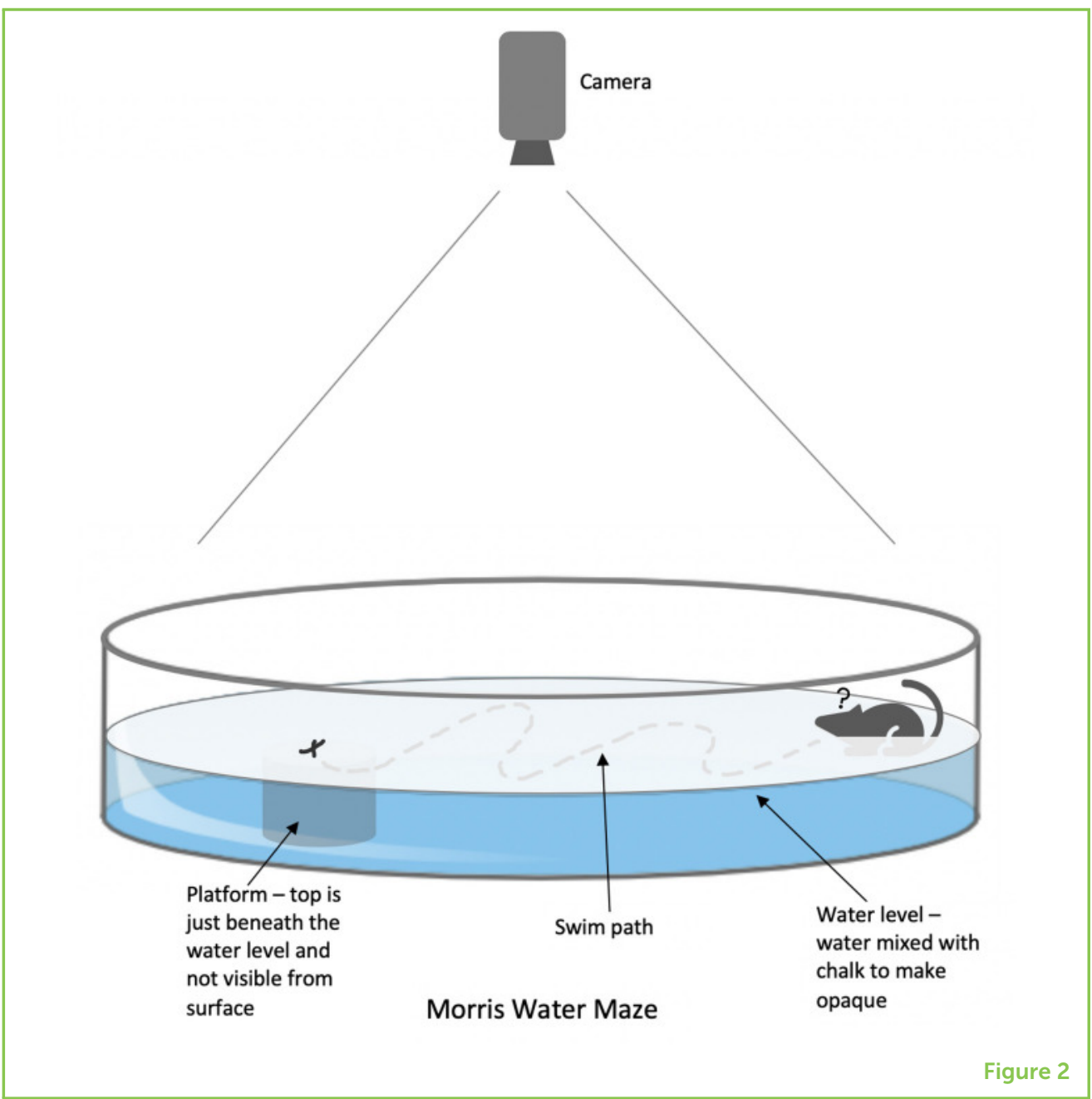

high for the rat to get out, so it swims around and around, looking for some other way out of the water.

In the Morris water maze tank, there is a platform placed just under the surface of the water. Once the rat finds the platform, it quickly climbs on. So, you would think that the next time the rat is put into the tank of water, it should just look for the platform and swim to it. That is exactly what the rat tries to do.

The Morris water maze is tricky, because the platform is hidden just below the surface of the water...and, to make it really hard, the water is colored with white chalk so that the rat cannot see the platform below the water's surface. So, even though the platform is always in the same location, it is actually hidden from the rat's view and the rat has to remember where the platform is located in the tank in order to find it quickly (Figure 2).

The first few times the rat is put into the tank, it learns where the platform is located in relation to the other objects that it can see in the room. Each time the rat is put into the tank, it searches quickly for 
TRAUMATIC BRAIN

INJURY

Any serious injury to the brain, often resulting from violence or an accident.

\section{EXPERIMENTAL/}

TREATMENT GROUP

VS. CONTROL

GROUP

In an experiment, two groups treated in the identical way except one group (treatment group) receives the intervention (drug or treatment) and the other does not (Control group).

\section{CLINICAL TRIAL}

A research study in humans to test the safety and how well a treatment or intervention works. the platform-remember, rats do not like to swim. The better the rat's memory and the better it learned from the last time it was put in the tank, the quicker and straighter it swims toward the platform.

We measure the distance of the path that the rat takes to the platform over several trials, to determine how "smart" a rat is, or how much memory the rat has.

\section{THE FINAL TEST}

In this experiment, the scientist tested several drugs to see if they could improve memory after a traumatic brain injury. First, they created a brain injury in a group of rats. These injured rats have trouble finding the platform each time they are put into the tank, even though they have been in the tank multiple times. This is because, due to memory problems caused by the brain injury, the rats were unable to learn or remember where the platform was located.

To test if the drugs improve memory, the rats are divided into groups based on which drug they got. For an example, the scientist used 10 animals per group (each animal within one group receives the same drug). If one of the drugs is working, then those rats will remember where the platform is located under the surface of the water and will swim straighter and faster to the platform. This is recorded as distance (how far the rat swam before it got to the platform) and time (how quickly it found the platform each time it was put in the maze). The distance (shorter path is better) and time (short time is better) are compared between each group of animals based on which drug they received and also compared with injured animals that did not received any drug (control group). If one of the groups did a lot better than the others and/or the control animals, then it means the drug improved the rats' memory and might be a new treatment for brain injury!

\section{CONCLUSION}

So, now you know how scientist can use rats to do experiments testing new drugs to help improve recovery from brain injury. Measuring improvement in memory using a water maze is an important tool for studying how well a drug works in animals. Once scientist identify what drugs are safe and work best in animals, they can then design larger clinical trials to test the treatment in humans.

\section{ACKNOWLEDGMENTS}

The author would like to thank Jessica Forsstrom for the artwork in Figures 1 and 2 . 
SUBMITTED: 06 January 2020; ACCEPTED: 22 July 2021;

PUBLISHED ONLINE: 06 September 2021.

EDITED BY: Robert T. Knight, University of California, Berkeley, United States

CITATION: Wright DW (2021) How Do You Test a Rat's Memory? Front. Young Minds 9:524646. doi: 10.3389/frym.2021.524646

CONFLICT OF INTEREST: The author declares that the research was conducted in the absence of any commercial or financial relationships that could be construed as a potential conflict of interest.

COPYRIGHT () 2021 Wright. This is an open-access article distributed under the terms of the Creative Commons Attribution License (CC BY). The use, distribution or reproduction in other forums is permitted, provided the original author(s) and the copyright owner(s) are credited and that the original publication in this journal is cited, in accordance with accepted academic practice. No use, distribution or reproduction is permitted which does not comply with these terms.

\section{YOUNG REVIEWERS}

DRUMMONDVILLE ELEMENTARY SCHOOL, AGES: 10-11

We are a grade 5 class, currently studying at Drummondville Elementary School (DES). We study in both English and French. Our class is very respectful of our planet and place great importance on recycling, and composting. We are a group of energetic students, who love sports, and love to move. Our classroom has a library filled with books that we love to read.

\section{AUTHOR}

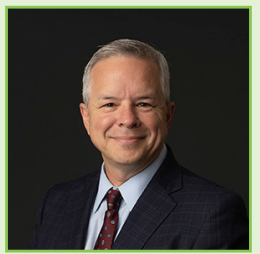

\section{DAVID W. WRIGHT}

Wright is a tenured Professor and the Chair of the Department of Emergency Medicine at Emory University School of Medicine. He is a board certified emergency medicine physician practicing at Emory affiliated hospitals and Grady Memorial Hospital, Atlanta's premier Level 1 Trauma Center. He is actively involved in both the preclinical and clinical assessments of traumatic brain injury, stroke and other acute neurological conditions. He was the PI of the ProTECT III multicenter clinical trial of progesterone for acute traumatic brain injury and serves as the southeastern Hub PI of the Neurological Emergencies Treatment Trials network, Co-PI of the Georgia StrokeNet network, and Hub PI for the newly funded Strategies To Innovate Emergency Care Clinical Trials Network (SIREN). He has extensive clinical trial leadership and operational experience. He holds Adjunct appointments in the Department of Biomedical Engineering at the Georgia Institute of Technology, Rollins School of Public Health, and the Nell Hodgson Woodruff School of Nursing. *david.wright@emory.edu 